\title{
Early palliative care for patients with metastatic lung cancer: Evidence for and barriers against
}

\author{
Chantal Bornais ${ }^{1 *}$ and Linda Deravin-Malone ${ }^{2}$ \\ ${ }^{1} \mathrm{RN}, \mathrm{BScN}$, The Ottawa Hospital, 501 Smyth Ave, Ottawa, ON, K1H 8L6, Canada \\ ${ }^{2}$ School of Nursing, Midwifery and Indigenous Health, Panorama Ave, Bathurst, NSW, 2795, Australia
}

\begin{abstract}
Aim: For newly diagnosed patients with metastatic lung cancer who receive their care in an ambulatory setting, questions relating to timing of referral to palliative care have been raised in the literature. This article examines these issues and formulates recommendations to further improve care for patients with newly diagnosed metastatic lung cancer.
\end{abstract}

Design: An integrated literature review

Method: Search terms included lung neoplasm, palliative care and referral and consultation. Full text articles in English between the years 2008 and 2014 were included. Titles and abstracts were reviewed to determine their suitability for inclusion in the review. Those that did not relate to metastatic non-small lung cancer, duplicates or those that only referred to end of life referrals were excluded.

Result: The initial search yielded 45 articles once inclusion and exclusion criteria were applied eleven articles were included in the review. Key themes that were identified were: time of referral to palliative care, stigma associated with the term palliative care, duration of chemotherapy, health care professional perceptions and attitudes to death and dying.

Conclusion: There is a need for planning end of life care in the early stage of diagnosis of this disease for these patients. Nurses working within a palliative care team are ideally placed to provide this supportive care and initiate this important conversation.

\section{Introduction}

The Canadian Cancer Society [1] estimates that approximately 26,100 new lung cancer cases will be diagnosed in Canada in 2014 and of that number, it is estimated that an overwhelming majority, 20500 or nearly $80 \%$, will die of this disease. Compared to other cancers in Canada, this represents the leading cause of death among all cancers at nearly double the death rate of the next most deadly cancer [1]. In Ontario, Canada, nearly $80 \%$ of all patients with lung cancer present at an advanced stage, yet no formal screening recommendations are available to facilitate earlier diagnosis of lung cancer [2].

According to the World Health Organization, 80 to $90 \%$ of lung cancer diagnoses can be attributed to cigarette smoking [3]. Cough, dyspnea and chest pain are commonly experienced by smokers and are also considered among the hallmark presenting symptoms for lung cancer [4]. Owing to the pervasiveness of these symptoms, many patients do not present until their cancer is at an advanced stage with metastatic disease rendering them ineligible for curative therapy. This patient population is commonly offered chemotherapy and radiotherapy for symptom management [4].

Current evidence suggests that referrals to palliative care services to assist with symptom management do not routinely occur in outpatient settings [5] and requests for palliative care are generally initiated at end of life when traditional treatment is discontinued or when patients are admitted to either hospital or hospice care [6,7]. With an estimated prognosis of less than one year from time of diagnosis [8], patients with metastatic lung cancer and their families have a relatively short period of time to adjust to their diagnosis and prepare for death.

\section{Aim}

For newly diagnosed patients with metastatic lung cancer who receive their care in an ambulatory setting, questions relating to timing of referral to palliative care including the benefits for patients or family and barriers to accessing services have figured prominently in the literature. This article proposes to examine these issues and formulate recommendations to further improve care for patients with newly diagnosed metastatic lung cancer.

\section{Method}

A literature search of OVID Medline (1946-present with daily updates) was performed using MeSH terms 'lung neoplasm', palliative care' and 'referral and consultation'. This search was further limited to articles published in 2008 to 2014 and yielded sixteen articles for inclusion in the review. Searching CINAHL with the same terms yielded nineteen articles and the Cochrane library offered ten articles. Within these search results there were duplicates and articles that focussed on end of life referral only, which were excluded. After a secondary review

Correspondence to: Chantal Bornais, RN, BScN, The Ottawa Hospital, 501 Smyth Ave, Ottawa, ON, K1H 8L6, Canada, E-mail: cbornais@toh.on.ca

Key words: metastatic lung cancer, palliative care, palliation, quality of life, survival benefit, end of life care

Received: July 02, 2016; Accepted: July 21, 2016; Published: July 25, 2016 
eleven articles were selected for inclusion in the literature review.

\section{Results}

From the identified articles for inclusion in this literature review key themes emerged from the data. These key themes were identified as: time of referral to palliative care, stigma associated with the term palliative care, duration of chemotherapy, health care professional perceptions and attitudes to death and dying, importance of patient education. Each of these themes will be discussed in turn.

\section{Discussion}

\section{Time of referral to palliative care}

Temel et al. [9] confirmed that adding early palliative care to standard oncological care for patients with metastatic non-small cell lung cancer is an essential component of standard oncological care. In this study, the provision of early palliative care delivered by palliative care physicians was initiated within three weeks of referral. This study concluded that there was a primary outcome change in quality of life (QOL) at twelve weeks and that there were significant improvements in many areas favouring the early palliative care group including overall survival [9].

QOL has been identified as an independent prognostic factor for survival in oncology patients [10,11]. As documented by Sloan et al. [12], QOL deficits at time of diagnosis of non-small cell lung cancer were found to be significantly associated with overall survival. Even after controlling for other factors compatible with overall survival such as performance status, older age, smoking history, male gender, treatment factors and stage of disease, QOL remained significant. These results may be explained by the fact that QOL encompasses more than just physical aspects of well-being. Psychological, social and spiritual well-being are also key components of QOL [13], as reflected by their inclusion in the World Health Organization definition of palliative care [14].

Consideration of referral to palliative care services at time of diagnosis of metastatic non-small cell lung cancer is also required. This is supported by a provisional clinical opinion from The American Society of Clinical Oncology who felt that although more research is needed in terms of impact on caregiver and societal outcomes, the current available evidence demonstrates that there is no evidence of harm to patients or caregivers nor is there excessive cost associated with early palliative care in this population [15]. The European Society for Medical Oncology [16] have been early adopters of this practice and offer accreditation for centers that provide integrated standard oncological care and palliative care, further solidifying the evidence that the current paradigm of care in North America requires change [17]. Lastly, changing the title of palliative care teams to supportive care teams may eliminate a barrier to referral to early palliative care within North America.

\section{Stigma associated with the term palliative care}

The Temel et al. [9] study benefitted from a recruitment approach rather than relying on physician referral to the palliative care service. University of Texas MD Anderson Cancer Center [18] noted that most referrals to palliative care occurred late in the disease trajectory and hypothesized that the name palliative and hospice care was itself a barrier to referral. They surveyed both midlevel providers and medical oncologists and found an overwhelming majority preferred the name supportive care to palliative care. Those surveyed felt that the team name provided a barrier to referral, decreased hope and caused distress to patients and their families [18]. Following this study, the team changed their name to supportive care and documented a forty-one percent increase in referrals. Although this study did not specifically address lung cancer physicians, the findings further support Temel $e t$ al. [10] reporting a survival benefit with early palliative care [19].

\section{Duration of chemotherapy}

A recent retrospective review performed in Japan examined survival time, duration of chemotherapy and post progression survival comparing patients receiving early palliative care referrals and those with late palliative care referrals [20]. This study further confirmed the Temel et al. [9] findings with the early palliative care cohort surviving 14 months as opposed to 3.5 months in the late palliative care cohort [20]. Post-progression survival was improved by two months in the early palliative care cohort, of the three disease sites studied; only the lung cohort was statistically significant in this area. It should be noted however that early palliative care extended the duration of chemotherapy by 4.1 months in the lung cohort and may have positively impacted the overall survival and post-progression survival data.

\section{Health professional perceptions and attitudes to death and dying}

With the majority of standard oncological care offered on an outpatient basis, a key issue is the need to integrate palliative care into the ambulatory setting; yet, physician tendency is to refer at end of life only. In a study conducted by Keating et al. [21], it was identified that most physicians including oncologists would wait until there were no further anti-cancer treatments to offer before referring a patient to palliative care. In this study physicians were comfortable discussing prognosis with a patient who was asymptomatic and who may have had four to six months of life expectancy. Keating et al. [21] also identified that physicians were reluctant to discuss topics such as DNR status, hospice placement or preferred site of death. This study confirms that physicians themselves are a significant barrier to patients accessing palliative care services.

It is acknowledged within the literature that health care providers receive little formal education in palliative care [22,23]. Owing to a declining workforce, all health care providers should have some baseline knowledge of the principles of palliative care and should be prepared to integrate palliative care into their daily practice [24]. Integration of palliative care knowledge in university level training for primary and tertiary health professions is paramount as is providing ongoing education at the institution level to promote wider acceptance of and earlier integration of palliative care in the disease trajectory for metastatic non-small cell lung cancer patients [25]. Advance practice palliative care nurses could fulfill this role for nursing.

The professional focus of nursing is care of the whole person rather than the disease and is therefore a natural choice for supportive care of patients with metastatic non-small cell lung cancer. It is widely accepted that nursing forms an important component of an interdisciplinary palliative care team. Bakitas et al. [26] demonstrated that patients receiving a multi-component nursing-led intervention consisting of education sessions and at least monthly telephone followup in tandem with usual care reported improved quality of life and mood. Counselling, increased frequency of assessment and social support may well account for the QOL and symptom improvements $[9,26]$ however, further research is needed to confirm this. 
Nurses have the potential to deliver care in all care settings: ambulatory, hospital and home care. Greater access to ambulatory palliative care is required and is another area where nursing could provide a greater contribution to holistic care and overcome barriers to access for patients and families [27].

\section{Importance of patient education}

While evidence available to date has documented a clear association between survival benefit and overall QOL [12] with early palliative care, psycho-educational support has also been implicated in improving QOL and mood in patients with advanced cancer [26]. Initial palliative care consultation time may be increased in highly symptomatic patients, however, this may serve to establish rapport and allow for earlier integration of prognosis and end-of-life discussions $[28,29]$ which may better prepare patients and families to plan for death. Furthermore, lung cancer physicians acknowledge a lack of comfort in managing symptoms patients find distressing and felt that a multi-disciplinary approach for this patient population would be beneficial [30].

Palliative care, with its focus on a multi-disciplinary approach $[31,32]$ is best suited to support patients and families as well as standard oncological care physicians. Indeed, Muir [33] explored the practice of having a palliative care specialist working within a busy oncology clinic for one half day weekly. Patient symptoms were tracked on the Edmonton Symptom Assessment Scale (ESAS) and a twenty one percent improvement was noted in those patients able to complete serial ESAS scales. The oncologists also reported increased satisfaction with their work $[33,34]$.

Temel et al. [9] also examined the perception of prognosis and goals of therapy. In this study patients felt they had curable disease and that the goal of therapy was to rid them of disease. Temel et al. demonstrated that early referral to palliative care services allowed for active participation in the decision-making process [9]. With the cost of health care escalating, the potential cost savings from integrating palliative care early in the disease trajectory also make this model of care worth consideration. Avoidance of futile end of life admissions to hospital, improved usage of hospice resources, unnecessary treatments are all sources of potential savings that could be realized by implementing early palliative care in a metastatic lung cancer population $[9,13,32]$.

\section{Conclusion}

Consideration should be given to implementing automatic referral for early palliative care for every patient newly diagnosed with metastatic non-small cell lung cancer. When one considers that the majority of health care costs occur in the final year of life and that the vast majority of this population will not survive one year, it is imperative that a change in the current care paradigm occurs. Nurses with adequate training in palliative care stand poised to provide the support patients and families require as well as offering symptom assessment and reinforcement of the goals of treatment for this patient group. Quality of life can be improved through symptom management and supportive care which has the ability to offer a survival benefit and a death that reflects patient wishes. Health care providers are encouraged to offer access to both palliative care and standard oncological care in the early stages of diagnosis of metastatic lung cancer. Doing this may improve both quality and length of life for this patient group.

\section{References}

1. Canadian Cancer Society's Advisory Committee on Cancer Statistics (2014) Canadian Cancer Statistics 2014. Toronto, ON.

2. Roberts H, Walker-Dilks C, Sivjee K, Ung Y, Yasufuku K, et al. (2013) Screening High-Risk Populations For Lung Cancer: Guideline Recommendations. J Thorac Oncol 8: 1232-1237.[Crossref]

3. World Health Organization (2015) Cancer Fact Sheet 297

4. Peters S, Adjei AA, Gridelli C, Reck M, Kerr K, et al. (2012) Metastatic Non-SmallCell Lung Cancer (NSCLC): ESMO Clinical Practice Guidelines For Diagnosis, Treatment And Follow-Up. Annals of Oncology 23: Vii56-Vii64.

5. Meier DE, Beresford L (2008) Outpatient Clinics Are A New Frontier For Palliative Care. J Palliat Med 11: 823-828.[Crossref]

6. Reville B, Miller MN, Toner RW, Reifsnyder J (2010) End-Of-Life Care For Hospitalized Patients With Lung Cancer: Utilization Of A Palliative Care Service. $J$ Palliat Med 13: 1261-1266.[Crossref]

7. Osta BE, Palmer JL, Paraskevopoulos T, PeiBL, Roberts LE, et al. (2008) Interval Between First Palliative Care Consult And Death In Patients Diagnosed With Advanced Cancer At A Comprehensive Cancer Center. Journal of Palliative Medicine 11: 51-57.

8. Non-Small Cell Lung Cancer Collaborative Group (2010) Chemotherapy And Supportive Care Versus Supportive Care Alone For Advanced Non-Small Cell Lung Cancer. Cochrane Database Syst Rev: CD007309.[Crossref]

9. Temel JS, Greer JA, Muzikansky A, Gallagher ER, Admane S, et al. (2010) Early Palliative Care For Patients With Metastatic Non-Small-Cell Lung Cancer. $N$ Engl $J$ Med 363: 733-742.[Crossref]

10. Gotay CC, Kawamoto CT, Bottomley A, Efficace F (2008) The Prognostic Significance Of Patient-Reported Outcomes In Cancer Clinical Trials. J Clin Oncol 26: 1355-1363. [Crossref]

11. Quinten C, Coens C, Mauer M, Comte S, Sprangers MAG, et al.(2009) Baseline Quality Of Life As A Prognostic Indicator Of Survival: A Meta-Analysis Of Individual Patient Data From EORTC Clinical Trials. Lancet Oncology 10: 865-871.

12. Sloan JA, Zhao X, Novotny PJ, Wampfler J, Garces Y, et al. (2012) Relationship Between Deficits In Overall Quality Of Life And Non-Small-Cell Lung Cancer Survival. J Clin Oncol 30: 1498-1504.[Crossref]

13. Irwin KE, Greer JA, Khatib J, Temel JS, Pirl WF (2013) Early Palliative Care And Metastatic Non-Small Cell Lung Cancer: Potential Mechanisms Of Prolonged Survival. Chronic Respiratory Disease 10: 35-47.

14. World Health Organization(2014) Cancer - WHO Definition of Palliative Care.

15. Smith TJ, Temin S, Alesi ER, Abernethy AP, Balboni TA, et al.(2012) American Society Of Clinical Oncology Provisional Clinical Opinion: The Integration Of Palliative Care Into Standard Oncology Care. Journal of Clinical Oncology 30: 880-887.

16. Cherny NI, Catane R, Kosmidis P, ESMO Taskforce on Supportive And Palliative Care (2003) ESMO Takes A Stand On Supportive And Palliative Care. Ann Oncol 14: 1335-1337.[Crossref]

17. Oncology, ESOM (2013) $10^{\text {th }}$ Anniversary Of ESMO Designated Centres Programme To Improve Palliative Care Services

18. Fadul N, Elsayem A, Palmer JL, Del Fabbro E, Swint K, et al. (2009) Supportive Versus Palliative Care: What's In A Name?: A Survey Of Medical Oncologists And Midlevel Providers At A Comprehensive Cancer Center. Cancer 115: 2013-2021.

19. Dalal S, Palla S, Hui D, Nguyen L, Chacko R, et al. (2011) Association Between A Name Change From Palliative To Supportive Care And The Timing Of Patient Referrals At A Comprehensive Cancer Center. Oncologist 16: 105-111.

20. Otsuka M, Koyama A, Matsuoka H, Niki M, Makimura C, et al. (2013) Early Palliative Intervention For Patients With Advanced Cancer. Jpn J Clin Oncol 43: 788-794. [Crossref]

21. Keating NL, Landrum MB, Rogers SO Jr, Baum SK, Virnig BA, et al. (2010) Physician Factors Associated With Discussions About End-Of-Life Care. Cancer 116: 998-1006. [Crossref]

22. Van Aalst-Cohen ES, Riggs R, Byock IR (2008) Palliative Care In Medical School Curricula: A Survey Of United States Medical Schools. Journal of Palliative Medicine 11: $1200-1202$

23. Ferrell B, Virani R, Paice JA, Coyle N, Coyne P (2010) Evaluation Of Palliative Care Nursing Education Seminars. Eur J OncolNurs 14: 74-79.[Crossref] 
24. Grant M, Elk R, Ferrell B, Morrison RS, Von Gunten CF (2009) Current Status pf Palliative Care-Clinical Implementation, Education, And Research. CA Cancer J Clin 59: 327-335.[Crossref]

25. Canadian Hospice Palliative Care Nursing Standards Committee (2014) Canadian Hospice Palliative Care Nursing Standards of Practice. Canada.

26. Bakitas M, Lyons KD, Hegel MT, Balan S, Brokaw FC, et al. (2009) Effects Of A Palliative Care Intervention On Clinical Outcomes In Patients With Advanced Cancer: The Project ENABLE II Randomized Controlled Trial. Journal of the American Medical Association 302: 741-749.

27. Prince-Paul M, Burant CJ, Saltzman JN, Teston LJ, Matthews CR (2010) The Effects Of Integrating An Advanced Practice Palliative Care Nurse In A Community Oncology Center: A Pilot Study. J Support Oncol8: 21-27.[Crossref]

28. Jacobsen J, Jackson V, Dahlin C, Greer J, Perez-Cruz P, et al. (2011) Components of Early Outpatient Palliative Care Consultation In Patients With Metastatic Nonsmall Cell Lung Cancer. J Palliat Med 14: 459-464.[Crossref]

29. Yoong J, Park ER, Greer JA, Jackson VA, Gallagher ER, et al. (2013) Early Palliative
Care In Advanced Lung Cancer: A Qualitative Study. JAMA Intern Med 173: 283-290. [Crossref]

30. Smith CB, Nelson JE, Berman AR, Powell CA, Fleischman J, et al. (2012) Lung Cancer Physicians' Referral Practices For Palliative Care Consultation. Ann Oncol 23: 382-387.[Crossref]

31. Mitra S,Vadivelu N (2013) Multidisciplinary Approach and Coordination Of Care. In: Vadivelu N, Kaye AD and Berger JM (Eds.) Essentials of Palliative Care.

32. Morrison RS, Dietrich J, Ladwig S, Quill T, Sacco J, et al. (2011) Palliative Care Consultation Teams Cut Hospital Costs For Medicaid Beneficiaries. Health Aff (Millwood) 30: 454-463.[Crossref]

33. Muir JC, Daly F, Davis MS, Weinberg R, Heintz JS, et al.(2010) Integrating Palliative Care Into The Outpatient, Private Practice Oncology Setting. Journal of Pain And Symptom Management 40: 126-135.

34. Tamborini M (2016) Malte Christian Ebach, Origins Of Biogeography. The Role Of Biological Classification In Early Plant And Animal Geography: Dordrecht, Heidelberg, New York, London: Springer, 2015, Xiv + 173 Pp., Hardcover 99,99 Â, ᄀ. HistPhilos Life Sci 38: 5.[Crossref]

Copyright: (C2016 Bornais C. This is an open-access article distributed under the terms of the Creative Commons Attribution License, which permits unrestricted use, distribution, and reproduction in any medium, provided the original author and source are credited. 